\title{
PRÁTICAS ORACULARES TIBETANAS: O CASO DO ORÁCULO NECHUNG
}

\author{
Ana Paula Martins Gouveia ${ }^{1}$ \\ Gregory A. Hillis ${ }^{2}$
}

\begin{abstract}
Resumo: Desde o tempo das práticas animistas/xamânicas nativas do Tibete pré-buddhista, a mediunidade tem sido difundida e exercido muita influência nos países da região do Himalaia. O presente artigo propõe-se a investigar o que acontece com a identidade do médium durante o período de transe, uma questão particularmente significativa no contexto do buddhismo tântrico que domina a região cultural do Tibete. Pretendemos então analisar o deslocamento temporário da identidade do oráculo, utilizando conceitos tradicionais deste contexto, a crítica buddhista de "pessoa" (skandhas), e a concepção filosófica de vacuidade (Śūnyatā) e do "não-eu" (anātman). Para tentar obter uma possível resposta a essa pergunta, vamos nos concentrar principalmente no oráculo Nechung, que é o oráculo do Estado Tibetano.
\end{abstract}

Palavras-chave: Buddhismo; Tibete; Práticas Oraculares; Filosofia.

Abstract: Since the time of indigenous pre-Buddhist animistic/shamanistic practices and beliefs, mediumship has been widespread and influential in Himalayan countries. The present paper will investigate what becomes of the usual identity of the medium during the trance period. This question is particularly vexing in the context of the unique blend of scholastic and tantric Buddhism that dominates the Tibetan cultural region. We will endeavor to analyze the temporary displacement of the oracle's identity by utilizing such traditional concepts as the standard Buddhist critique of person (skandhas), and the philosophical concept of emptiness (śūnyatā) and selflessness (anātman). To try to raise a possible answer to this question we will primarily focus on the Nechung Oracle, the State Oracle of Tibet.

Keywords: Buddhism; Tibet; Oracular Practices; Philosophy.

1 Pós-doutoranda na Universidade de São Paulo, Brasill; Professora da Escola Superior Artística do Porto, Portugal. Contato: apaulamg@usp.br.

2 University of California Santa Barbara. Continuing Lecturer Sanskrit and Tibetan. USA. Contato: ghillis@religion.ucsb.edu.

Debates do NER, Porto Alegre, ano I5, N. 25, P. 29I-3IO, Jan./Jun. 20 I4 


\section{INTRODUÇÃO}

A inspiração inicial para a nossa pesquisa veio de uma fonte bastante inesperada. Em um documentário recente sobre o Oráculo do Estado Tibetano, o Oráculo Nechung (tib. gnas chung) ${ }^{3}$ intitulado The Oracle: Reflections on Self (2007), o cineasta canadense David Cherniack coloca uma questão intrigante: o que acontece com a consciência do médium durante o transe? Tal questão é ainda mais relevante se pensarmos na tradição buddhista ${ }^{4}$ tibetana, que se dedica intensamente sobre a análise psicológica e crítica do indivíduo e da personalidade, com o "self". Ao ponderarmos sobre esta questão, e as várias outras indagações que surgiram em conexão com a mesma, ocorreu-nos que, indubitavelmente, questionamentos semelhantes devem surgir, ainda que perifericamente, em qualquer tradição que inclua possessão por espíritos, como o xamanismo, as sessões espíritas, o candomblé, umbanda etc. De qualquer forma, dentro da tradição buddhista, esta questão nos parece especialmente relevante, posto que estamos nos referindo a um universo onde a preocupação com questôes relativas à identidade e à consciência são fundamentais.

Quando começamos as nossas pesquisas preliminares, ficamos surpresos ao constatar que não havia praticamente nenhum material teórico diretamente ligado a esta questão específica, ou mesmo descrições mais genéricas ou análises, dentro da literatura tradicional tibetana que até então nos é conhecida. Há, todavia, uma riqueza relativamente grande de narrativas sobre as bases mitológicas dos espíritos mais conhecidos, em especial, sobre

3 As nomenclaturas entre parênteses estarão em grande parte relacionadas ao termo em tibetano, escritos de acordo com método de transliteração desenvolvido por Turrell V. Wylie. A terminologia em sânscrito será precedida pela letra s.

4 O termo "buddhista", muito embora conste do dicionário com apenas um "d" e sem o " $h$ " (isto é, budista), é originário da palavra Buddha em sânscrito, que é composta pelas sílabas "bu + ddha", a palavra sem essas duas letras teria outro significado. É importante lembrar que estamos tratando de um termo estrangeiro, e a mera adaptação fonética, em termos de sonoridade, não é o suficiente para nos remeter ao sentido original da palavra. Uma explicação mais detalhada sobre o assunto poderá ser encontrada brevemente em meu livro Como Ler Filosofia Buddhista (Gouveia), a ser lançado pela editora Paulus em 2014.

Debates do NER, Porto Alegre, ANo I5, N. 25, P. 29I-3IO, JAN./Jun. 2014 
as entidades que foram convertidas ao buddhismo, e também sobre os episódios em que os espíritos se manifestam através de posses espontâneas, i.e., sem que o/a médium necessariamente saiba que o espírito irá se apossar do seu corpo, ou qual é o espírito que está se utilizando do corpo do hospedeiro. Além deste material, também foi possível encontrar um vocabulário conceitual bastante rico, através de entrevistas e estudos sobre médiuns contemporâneos feitos por especialistas, o que foi capaz de aprimorar o nosso conhecimento sobre as explicações tradicionais a respeito do processo. Muitos dos termos aparecem expressos não só no material pré-buddhista, mas também naquilo que poderia ser descrito como fontes "tântricas", mais do que aquilo que fora encontrado no vocabulário estritamente filosófico 5 . De forma complementar, há uma relativa riqueza de literatura ritualística focada na invocação, conciliação, ou adoração das deidades oraculares ${ }^{6}$.

5 Em John Vincent Bellezza (2005) Spirit-mediums, Sacred Mountains and Related Bon Textual Traditions. In: Upper Tibet: Calling Down the Gods (p. 7-8, 32 et passim), podemos encontrar um impressionante volume que se baseia em material textual e também sobre um extenso trabalho de campo realizado entre médiuns contemporâneos nas regiôes tibetanas de Töd (tib. stod) e Changthang (byang thang), bem como em áreas culturais tibetanas estabelecidas na Índia e no Nepal. Através de seus informantes, ele é capaz de identificar vários termos muito úteis para teorizar o fenômeno de posse oracular que ocorre nos Himalaias, os quais parecem ser bastante apropriados à terminologia usada em fontes tântricas. Entre as mais marcantes, estão o uso dos termos "raios de luz" ('o zer) para se referir à divindade que os possui, e "canais" (rtsa) para se referir às artérias sutis no corpo do médium, que fornecem a base física para a divindade/espírito. O oráculo Nechung usa o termo "ser de sabedoria" (ye shes sems dpa ') para se referir à consciência da divindade que o possui durante o transe, ou seja, Pehar.

6 No caso específico do espírito de Pehar (pe har), a divindade de cinco formas canalizada pelo oráculo Nechung, existem vários desses textos rituais datados, sobretudo, do século XVII ao século XX. Grande parte desses textos tiveram sua origem a partir das escolas Geluk (dge lugs) e Nyingma (rnying ma), muito embora também existam alguns provenientes de outras escolas. Alguns desses textos foram compostos por figuras históricas importantes, como o chamado "Grande Quinto" - que foi o quinto Dalai Lama, Ngawang Lozang Gyatso (ngag dbang blo bzang rgya mtsho, 1617-1682) -, Karma Chakmé (karma chags med, 1613-1678), Cangkya Rölpe Dorje (lcang skya rol pải rdo rje, 1717-1786) e Thuken choki Nyima (thu’u bkwan chos kyi nyi ma, 1737-1803).

Debates do NER, Porto Alegre, ano I5, N. 25, P. 29I-3IO, Jan./Jun. 20 I4 
Entretanto, uma literatura teórica ou filosófica que aborde estas questões de forma direta é notavelmente ausente.

Uma das possíveis razôes para esta ausência pode estar ligada ao fato de que a tradição de práticas mediúnicas no Tibete precede o advento do buddhismo, e é até hoje mais predominante nas comunidades nativas chamadas "Bön" do que entre os buddhistas, sendo que entre os últimos é que se pode encontrar um meio sob o qual as indagaçóes filosóficas foram particularmente desenvolvidas. De fato, parece muito provável que mesmo os oráculos buddhistas mais proeminentes (incluindo o Nechung) - e as práticas associadas a eles -, os quais são utilizados no contexto monástico tibetano, estão diretamente relacionados aos seus precursores locais não buddhistas. Esta relação reflete-se em seus instrumentos rituais, suas vestimentas e, acima de tudo, na estrutura sob a qual a possessão acontece, os quais são praticamente idênticos em ambas as tradições. Na verdade, a grande maioria dos espíritos oraculares utilizados no buddhismo tibetano tem pedigrees explicitamente não buddhistas.

De qualquer maneira, fica evidente que as formas de buddhismo associadas ao discurso lógico e epistemológico se esquivaram, ou foram incapazes, de se envolver em uma crítica teórica e análise desta forma alternativa de observância religiosa, a qual não é facilmente redutível a estratégias de racionalização. De fato, essas duas orientações religiosas parecem ser um tanto quanto incompatíveis, muito embora tenham coexistido, com um certo desconforto, enquanto parceiras dentro do contexto religioso tibetano durante séculos. Apesar desta aparente incongruência e a ausência de qualquer evidência de envolvimento direto entre estas vertentes discursivas, a tradicional investigação filosófica buddhista apresenta-se singularmente bem adaptada para interpretar a dinâmica psicofísica de todo o processo de possessão e transe. Com base nesse fato, decidimos tentar criar uma interpretação preliminar do fenômeno de possessão a partir dos termos e conceitos que fazem parte das próprias tradições intelectuais do buddhismo tibetano, e aplicá-las ao caso específico do oráculo Nechung, o mais importante oráculo do Estado Tibetano.

Debates do NER, Porto Alegre, ANo I5, N. 25, P. 29I-3IO, JAN./Jun. 2014 


\section{CONTEXTO}

Hoje em dia tornou-se quase um truísmo a afirmação de que a forma de buddhismo pela qual a região cultural tibetana é mais conhecida representa uma combinação única das doutrinas e práticas provenientes de um buddhismo indiano tardio associadas às crenças e aos rituais nativos pré-existentes, por vezes identificados como "Bön" (bon). E, de fato, o panteão buddhista tibetano assimilou um número significativo de divindades locais, espíritos, guardiōes etc., além de adotar muitas das preocupaçōes dos grupos religiosos nativos, entre as quais a pacificação dos espíritos maléficos, a veneração das montanhas, os ritos fúnebres, a adivinhação e assim por diante. Sendo assim, a forma mais característica do buddhismo tibetano incorpora uma mistura distinta de elementos do buddhismo tântrico e escolástico com as tradições religiosas nativas. Além disso, esta não tem sido uma comunicação unilateral, práticas locais da região do Himalaia têm sido profundamente influenciadas pelo encontro com o buddhismo, a tal ponto que acabou por ser gerada uma literatura ligada tanto às instituições religiosas nativas formais quanto a uma religiosidade híbrida, um feito sem qualquer precedente anterior à penetração buddhista (Kapstein, 2000, p. 10-17).

Para além da afinidade evidente e dos pontos de contato entre o buddhismo tântrico da Índia medieval e as práticas xamânicas/animistas do Tibete pré-buddhista, é preciso também levar em conta o papel que a vertente escolástica racionalista do buddhismo indiano desempenhou no desenvolvimento do buddhismo tibetano. O discurso tântrico, com sua ênfase na subjugação e na transmutação dos poderes demoníacos - que, na verdade, dentro de seu próprio contexto, nada mais são do que a própria percepção do praticante, desprovidos de qualquer realidade intrínseca -, interpretado de forma literal, parece se prestar bem às preocupaçōes metafísicas e existenciais da sociedade dos Himalaias, particularmente as inquietações ligadas às forças naturais e psíquicas invisíveis. Por outro lado, o discurso acadêmico típico do buddhismo indiano monástico não teve qualquer conexão com as práticas pré-buddhistas do Tibete. Dentro deste contexto acadêmico e/ou monástico, encontramos um conjunto complexo e sofisticado de investigaçóes racionais

Debates do NER, Porto Alegre, ano I5, N. 25, P. 29I-3IO, Jan./Jun. 20 I4 
de vertente psicológica, ontológica e metafísica baseadas em sūtras e śāstras (tratados) buddhistas, os quais estavam principalmente preocupados com a explicação do mundo e seu conteúdo, ou seja, o meio ambiente e as formas variadas sob as quais vivem os seres sencientes.

A aparente disjunção entre essas duas orientações fundamentalmente distintas em relação à vida religiosa que caracteriza o buddhismo em toda a região do Himalaia tem sido amplamente comentada e analisada por estudiosos antigos e contemporâneos, os quais frequentemente justapóem tais diferenças em um espectro com termos diádicos como "razão" versus "revelação", ou "clerical" versus "xamânico"”.

Quando as diversas e sofisticadas formas do buddhismo indiano apareceram no Tibete, tornou-se necessário um ajuste entre as divindades alienígenas do panteão buddhista e as das tradições nativas. Uma dimensão importante com a qual a recém-chegada religião teve que se deparar, foi justamente a dos cultos altamente desenvolvidos ligados a guardióes e espíritos oraculares das tradições indígenas do Tibete, sendo que grande parte desses cultos se mantêm até os dias de hoje, como pode ser visto nos estudos realizados por Bellezza (2005). Nessas formas de prática, um médium conhecido como um lha pa, ou lha babs mkhan (entre outras terminologias), canaliza os espíritos desencarnados dos deuses, (lha), das nagas (klu), de demônios ('dre), de deuses da montanha (lha ri), de deusas do lago (lha mtsho), de espíritos guerreiros (dgra lha), etc., com a finalidade de cura, adivinhação, arbitragem de disputas, e assim por diante ${ }^{8}$.

Dentro dos parâmetros hermenêuticos, os representantes do buddhismo esforçaram-se tanto para absorver quanto para dominar a população indígena de divindades, demônios e espíritos através da imposição de uma estrutura

7 Ver Geoffrey Samuel, Civilized Shamans: Buddhism in Tibetan Societies (Washington DC: Smithsonian Institute Press, 1993), assim como Steven Goodman e Ronald Davidson, Tibetan Buddhism: Reason and Revelation (Albany NY: SUNY Press, 1992). Samuel explicitamente faz uma correlação entre o buddhismo tântrico de India com o xamanismo tibetano pré-buddhista.

8 A taxonomia das divindades e dos espíritos tibetanos é ainda pouco compreendida e é uma área bastante promissora para novas pesquisas.

Debates do NER, Porto Alegre, Ano I5, N. 25, P. 29I-3IO, JAN./Jun. 2014 
interpretativa hierárquica sobre as deidades locais. A instituição dessa estrutura deu-se através da distinção entre as chamadas deidades "mundanas" (“jig rten pa’i lha) e as "supramundanas” (“jig rten las 'das pa’i lha). Em termos buddhistas, a característica distintiva chave entre divindades é que as supramundanas, assim como alguns dos protetores, devem ser entendidos como iluminados e exclusivamente preocupados com as suas funções soteriológicas, enquanto as divindades mundanas estão presas à existência cíclica (s.: saṃsāra) e focadas em preocupações limitadas a este mundo.

As divindades dos escalóes mais baixos desta hierarquia também são altamente estratificadas e numerosas demais para serem detalhadas neste estudo, de qualquer forma, dentre as mais elevadas e poderosas divindades "mundanas", estão os chamados "espíritos guerreiros" (rgyal po), geralmente reconhecidos como espíritos de reis malévolos, ou de lamas (bla ma, sacerdotes) que quebraram os seus votos. Provavelmente, o mais famoso dentre todos esses "espíritos guerreiros" seja Pehar (pe har), acompanhado por quatro outros espíritos guerreiros, conhecidos coletivamente como os "cinco espíritos guerreiros" (rgyal po sku lnga). É justamente para o espírito de Pehar, e os seus asseclas, que o já mencionado oráculo Nechung serve como o principal médium (sku rten).

\section{PEHAR E O ORÁCULO DE NECHUNG}

A antiga lenda do chamado "espírito guerreiro" Pehar, junto à sua consorte, é complexa e controversa, além de frequentemente contraditória. De acordo com uma das versões, Pehar era uma figura ambígua antes de sua conversão ao buddhismo, ele se manifestava em uma variedade de formas, tais como um monge ou um pássaro, com o intento de perturbar o equilíbrio de monges e leigos, através de suas interferências e da divulgação herética dos ensinamentos 9 . Todavia, a imaginação popular tibetana apresenta uma narrativa relativamente coerente e é geralmente aceita. Segundo esta tradição,

9 Ver Lin Shen-Yu, Pehar: A Historical Survey. In: Revue d'Etudes Tibétaines Paris. v. 19 Oct. 2010. v. 19. p. 6-7; e também Dan Martin, The Star King and the Four Children

Debates do NER, Porto Alegre, ano I5, N. 25, P. 29I-3IO, Jan./Jun. 20 I4 
Pehar foi recrutado como um protetor da religião buddhista no final do século VIII pelo lendário "fundador" do buddhismo tibetano, o mestre indiano Padmasambhava (pad ma 'byung gnas). Nos textos dos séculos XII e XIV, Pehar é descrito como sendo originalmente um espírito guerreiro estrangeiro, residente em Bhata Hor, que foi atraído por Padmasambhava para o Mosteiro de Samyé (bsam yas) com a perspectiva de adquirir joias e outras riquezas ${ }^{10}$. De acordo com estas fontes, Padmasambhava derrota Pehar e a sua horda de demônios ao "dar o seu comando e os atar por juramento" (bka' dang dam la gtags ${ }^{11}$.

De acordo com este relato tradicional, alguns séculos depois de ter sido nomeado como o guardião do tesouro e guardião geral de Samyé, Pehar partiu em direção ao Tibete central. O historiador tibetano do século XV, Gö Lotsāwa ('gos lo tsā ba gzhon nu dpal, 1392-1481), menciona que foi no século XII que Pehar possuiu um hospedeiro humano pela primeira vez $^{12}$. No século XVII, Pehar muda-se de Samyé para o Mosteiro Nechung (gnas chung dgon pa), o qual ficava a uma curta distância do Mosteiro

of Pehar: Popular Religious Movements of 11th-12th-Century Tibet. In: Acta Orientalia Academiae Scientarium Hungaricae. Budapeste, 1996. p. 177-178.

10 Se o guerreiro veio de fato de Bhata Hor é assunto de muitos debates. "Hor" é frequentemente usado como um termo genérico para se referir a Mongólia. Todavia, tradicionalmente, estudiosos tibetanos alegam que "Bhata Hor" se refere a um local em Bengala, no Paquistão, na Mongólia, na Ásia Central, ou mesmo na China. Ver Lin Shen-Yu, "Pehar", 19.

11 Ver o capítulo vinte de Nyangral Nyima Öser, bka' thang zangs gling ma, in: rin chen gter mdzod chen mo (New Delhi: Shechen Publications, 2007-2008), 114-115. Para uma tradução em inglês, ver Erik Hein Schmidt (tradutor), The Lotus Born: The Life Story of Padmasambhava. Boston: Shambhala, 1993, 132.

12 Ver George Roerich (tradução) The Annals Blue (Calcutá: Royal Asiatic Society, 1949), 80; e René Nebesky-Wojkowitz, Oracles and Demons of Tibet: The Cult and Iconography of the Tibetan Protective Deities (Kathmandu: Book Faith India, 1993), 104-105. Nebesky-Wojkowitz diz que este evento ocorreu no século XVI, enquanto Roerich localiza-o no século XII. Tendo em conta que o autor dos Blue Annals, Gö Lotsāwa, morreu no século XV, a data anterior parece muito mais plausível, i.e., no século XII, muito embora existam outras versões que sugerem que o seu aparecimento teria ocorrido no próprio século VIII, quando ele fora subjugado.

Debates do NER, Porto Alegre, ANo I5, N. 25, P. 29I-3IO, JAN./Jun. 2014 
Drepung ('bras spungs dgon pa), não muito longe de Lhasa. Foi durante o governo do chamado "Grande Quinto" Dalai Lama (ngag dbang blo bzang rgya mtsho, 1617-1682), que Pehar, através do espírito de Dorje Drakden (rdo rje drags ldan) que era seu emissário, começou a falar se utilizando do médium Nechung, o qual, de acordo com esta versão, tornou-se oficialmente reconhecido como o "Oráculo do Estado", estabelecendo então uma relação especial com o Dalai Lama que atravessaria séculos e dura até os dias de hoje.

Os oráculos tibetanos são geralmente conhecidos como médiuns de uma divindade específica, mas muitos são os casos em que múltiplas divindades são canalizadas em um único transe ${ }^{13}$. Acredita-se que o transe ocorra quando a divindade descende (babs) no oráculo, resultando em uma transformação na aparência e no comportamento do médium. No caso de deidades coléricas, o rosto do/a médium fica vermelho e os seus movimentos tornam-se muito violentos e erráticos. Tais "induçôes" são quase sempre acompanhadas de um ritual bastante elaborado, do qual fazem parte canções, visualizações e instrumentos como sinos, tambores, trombetas, componentes da orquestra litúrgica tibetana. No caso dos "oráculos do estado" (como o Nechung) e outros oráculos de alta estatura, esse esplendor formal é complementado por figurinos e adereços elaborados, que em geral são bastante similares às estilizadas armaduras do Período Imperial tibetano (circa 610-910 EC). O oráculo do estado sempre usa uma espécie de couraça altamente polida, que é referida como sendo um "espelho" (me long), com uma "sílaba semente" (sa bon. s. bīja) mântrica impressa sobre a mesma.

\section{HIPÓTESE - PREOCUPAÇŌES INICIAIS}

Um dos termos tibetanos mais comuns para a palavra "oráculo" (sku rten) pode nos fornecer uma pista ligada à nossa preocupação inicial sobre o que ocorre com a consciência do médium no momento do transe. A palavra tibetana kuden (sku rten), literalmente traduzida como "suporte físico",

${ }^{13}$ Ver Christopher P. Bell, "Tsiu Marpo: The Career of a Tibetan Protector Deity”. Dissertação de mestrado, Florida State University, 2006. p. 115.

Debates do NER, Porto Alegre, ano I5, N. 25, P. 29I-3IO, Jan./Jun. 20 I4 
já sugere que o médium proporciona uma base física (i.e., o hospedeiro humano) para o espírito, ou divindade, que está sendo hospedado. Outro termo comumente empregado para médiuns é lhapa (lha pa), que parece ser uma contração do termo mais completo lha babs mkhan, literalmente, "aquele sobre quem o deus descende" (Bellezza, 2005, p. 4). Com base nestas explicações tradicionais, fica claro que a consciência do oráculo é entendida como tendo sido subordinada, submersa ou deslocada pela poderosa identidade do espírito durante o transe.

Estas questôes relativas à identidade assumem ainda maior complexidade, quando consideradas dentro do contexto das tradições buddhistas em geral, e do buddhismo tibetano em particular. Isso ocorre porque uma dimensão crítica da filosofia buddhista se preocupa justamente com a análise, a crítica e a refutação da personalidade ou da identidade. Em suma, a visão buddhista, compartilhada pela maior parte de suas escolas filosóficas, diz que as pessoas não possuem uma identidade individual fixa ou estável; ao invés disso, há um fluxo constante de eventos mentais e físicos interdependentes e transientes conhecidos como os cinco agregados (s. skandhas), que são baseadas em causas e condições e convencionalmente designam aquilo que percebemos como sendo uma "pessoa" (s. pudgala). Muito embora esta designação convencional possa ser útil para fins práticos, para a elite das tradições buddhistas, o fato mais importante é que, em termos últimos, não existe tal coisa como o "self" (s. ātman -"eu"). Dessa forma, do ponto de vista estritamente filosófico, um médium, ou um oráculo, que canalize um espírito, desde o princípio, jamais teve uma individualidade independente e fixa a ser transformada, sublimada ou deslocada.

No presente contexto, a teoria do "não-eu”, ou do "não-si”" (s. anātman), sugere que o que é colocado em suspensão no momento da possessão não é exatamente o "eu" do médium, mas sim a ideia de um "eu". Em certo sentido, a afirmação de que ocorre a ausência de uma pessoa concreta, a qual deveria, de alguma forma, ser notada durante o transe, torna irrelevante a questão do que acontece com o fluxo de agregados (s. skandhas) do médium durante este processo. Afinal de contas, se não há qualquer "eu" duradouro ou permanente, a questão de para onde ele vai durante a sessão

Debates do NER, Porto Alegre, ANo I5, N. 25, P. 29I-3IO, JAN./Jun. 2014 
oracular nem sequer é colocada. E, no entanto, dada a premissa de que um médium é percebido como um indivíduo que, devido a uma variedade de causas e condiçôes, é capaz de "hospedar" uma entidade completamente separada a sua própria e permitir que tal entidade tenha voz através dele, parece perfeitamente razoável perguntar: "Quem acolhe quem?"

Do ponto de vista teológico, precisamente a ausência de uma identidade concreta e fixa pode ser entendida como capaz de facilitar a deslocação do que é, em última instância, um "eu” fictício durante o estado de transe. Este conceito buddhista amplamente aceito do "não-eu" (não-si”) também serve como base para uma outra concepção crítica conhecida como "vacuidade" (s. Súnyatā). De forma extremamente concisa, podemos dizer que a conceitualização de vacuidade sugere que todos os fenômenos nada mais são do que redes complexas de causas e condições interdependentes e, como tal, são desprovidos (i.e., são "vazias de") de uma existência autônoma e permanente. Na verdade, é muito fácil ver como essa falta de existência inerente se estende à lógica do "não-eu" (ou "não-si”) discutida anteriormente, para abranger não apenas pessoas, mas todo e qualquer fenômeno. Muito embora o princípio da vacuidade levante uma série de objeções até mesmo entre buddhistas, também é possível argumentar que a flexibilidade sugerida em uma radical ausência de existência inerente, proporciona uma maior liberdade para a transformação e recontextualização do "self" aparentemente estático ou permanente. Dessa maneira, o "eu" do espírito seria capaz de temporariamente possuir um "eu" humano com relativa facilidade, posto que as fronteiras aparentemente rígidas das identidades são, de fato, fluidas e permeáveis em virtude de sua vacuidade. A própria vacuidade é muitas vezes descrita como sendo uma condição dinâmica de abertura e potencialidades, e não um de vazio estéril. Nesse sentido, talvez as tradicionais estratégias interpretativas buddhistas sobre o "não-si" e sobre a vacuidade utilizadas para ponderarmos sobre o problema da identidade do oráculo, possa ser melhor traduzida em nosso próprio idioma como a distinção entre um "estado" estático versus um "processo" dinâmico interativo (Ellingson, 1998, p. 52).

Debates do NER, Porto Alegre, ano I5, N. 25, P. 29I-3IO, Jan./Jun. 20 I4 


\section{O PROCESSO}

Após essa breve e necessária introdução aos conceitos que afetam a nossa pesquisa, voltamos à nossa questão inicial: $\mathrm{O}$ que acontece com a identidade do médium durante o processo de incorporação? Infelizmente, como mencionado, no momento, não estamos cientes de qualquer fonte teórica de origem tibetana que aborde diretamente essa questão. Estudiosos de outras tradiçôes, que também investigaram práticas de possessão e transe em que um corpo é temporariamente "usado" por outra entidade, como Claude Lévi-Strauss (1963), IM Lewis (2003), entre tantos outros, não especularam sobre este tópico, pelo menos não da forma que nos propusemos neste estudo. Usamos a palavra "especular", pois, no momento, ainda não se pode "cientificamente" confirmar, com toda a certeza, o que acontece durante o processo. No entanto, como acontece com qualquer teoria acadêmica, temos de começar com uma hipótese.

No caso bastante específico do oráculo Nechung, sugerimos que essa possessão não seja meramente uma questão de crença, mas de fato. Como monge ordenado e altamente qualificado, Thupten Ngodrup, o atual médium de Dorje Drakden, tem votos monásticos estritos, o que o obrigaria a dizer a verdade em toda e qualquer circunstância e ele, provavelmente, jamais "mentiria" sobre as suas experiências. Além disso, mesmo que fosse capaz de fazê-lo, ele nunca seria capaz de realizar as proezas que executa quando possuído, apenas com as suas capacidades fisiológicas habituais. Este é um ponto crítico, que nos permite criar uma variedade de explicações possíveis. Para efeito dessa exposição, vamos nos concentrar em apenas uma delas.

Durante as sessóes de transe do oráculo Nechung, ele é capaz de usar um capacete extremamente pesado (dbu rmog), que em condições normais (i.e., se ele tivesse apenas com suas qualidades corporais habituais) quebraria o seu pescoço, devido ao seu enorme peso, as estimativas são variáveis, mas, em geral, são por volta de pelo menos $20 \mathrm{~kg}$ ou mais (Nebesky-Wojkowitz, 1993, p. 411). Como isso é possível? Como é possível que um mesmo corpo, em outro estado, ou controlado por uma outra consciência, possa suportar o peso de algo além de suas próprias "capacidades naturais"?

Debates do NER, Porto Alegre, ANo I5, N. 25, P. 29I-3IO, JAN./Jun. 20 I4 
A súbita transformação do corpo do oráculo - a tal ponto que ele se torna capaz de realizar atos dramaticamente além de suas forças - assemelha-se a casos em que pessoas comuns, em situações de emergência, de repente tornam-se capazes de levantar um carro, por exemplo, ou lutar contra um urso polar - a fim de salvar a própria vida ou a de uma outra pessoa -, sem qualquer preparação física específica ou predisposições fisiológicas extraordinárias, em uma manifestação espontânea do que é muitas vezes classificado como "força histérica" (hysterical strength) ou "delírio agitado" (excited delirium $)^{14}$.

Todavia, neste caso específico, estamos tratando de uma questão muito particular relacionada com a supressão ou deslocamento temporário de fatores psicológicos do médium, o qual envolve simultaneamente o corpo. Tentamos compreender este fenômeno específico à luz da lógica de conceitos filosóficos buddhistas relativos ao "não-si" (s. anātman) e a vacuidade (s. śūnyatā), os quais já foram mencionados anteriormente. A partir desses conceitos, sugerimos que o corpo não é tão "material" como a maior parte de nós costuma acreditar. Quando nos referimos a "material", ao invés de considerar a "materialidade" em termos convencionais, vamos nos concentrar apenas nas teorias filosóficas dentro deste contexto específico do buddhismo, para podermos explorar a possibilidade de uso do corpo de alguém por uma outra consciência e, assim, levantar uma hipótese ${ }^{15}$.

${ }^{14}$ Como exemplo de incidentes deste tipo, ver: CNN Wire Staff, 'Woman Lifts Car, Saves her Father'. Disponível em: http://edition.cnn.com/2012/08/01/us/virginia-daughter-saves-dad/index.html. Acesso em: 1 Aug. 2012.

15 Para um estudo específico da relação de conceitos buddhistas sobre a materialidade e as novas teorias da física quântica, em que a materialidade das coisas e dos fenômenos também é questionada, ver: B. Alan Wallace, (ed.), Buddhism and Science: Breaking New Ground (New York: Columbia University Press, 2003).

Vale lembrar ainda que a literatura sobre Estados Alterados de Consciência, de modo geral, traz muitas informações a este respeito, mas é importante ressaltar que estamos nos focando no caso específico deste oráculo, e tentando um entendimento diferente das abordagens já existentes. A proposta aqui é de trazer uma alternativa de interpretação a partir de conceitos oriundos da tradição indo-tibetana.

Debates do NER, Porto Alegre, Ano I5, N. 25, P. 29I-3io, JAn./Jun. 2014 
Neste contexto, o que chamamos de "pessoa" é entendido como um continuum de fenômenos mentais e físicos condicionados que carecem de uma essência subjacente, é um conjunto de processos psicofísicos que se encontram em constante mutação. Os elementos que constituem este processo são os cinco agregados (s. skandhas): forma (s. rūpa), sensações (s. vedanā), percepções (s. samjn̄ā), formações (s. samskāra) e consciência (s. vijñāna). A partir desta perspectiva, sugerimos que dentre esses cinco elementos, apenas a forma física (rūpa), i.e., o corpo, parece permanecer durante a posse total, todos os outros quatro agregados (que são os componentes mentais) parecem "desaparecidos" durante o transe. Vale ainda lembrar que esse corpo que percebemos não é uma forma estática que se mantém ali e é ocupada por uma outra consciência, como, metaforicamente, seria uma casa que é habitada por uma pessoa, esta vai embora, e depois um outro alguém instala-se naquele local. Não é isso, esse corpo ao qual nos referimos é um corpo em processo de constante transformação.

Se o "eu" é na verdade um processo - não uma entidade sólida ou uma essência - e se esse "eu" também é algo composto por partes que se separam por sua própria natureza, parece-nos razoável conjecturar que o corpo do Nechung (i.e., o agregado da forma - rūpa), em seu fluxo contínuo, continua "presente" durante o estado de transe, enquanto os outros elementos (agregados) psicológicos são temporariamente suprimidos, deslocados, ou permanecem presentes em um aspecto extremamente sutil, que possibilitaria a "invasão" do espírito. Thupten Ngodrup, o atual oráculo Nechung, usa a seguinte analogia para descrever o que acontece com a sua própria consciência no momento de transe. É como se, diz ele, "[...] o corpo sofresse um poderoso choque elétrico, o corpo ainda está lá, mas tudo parece ser dominado pela potência da eletricidade durante o choque" ${ }^{16}$. É como se o espírito superpoderoso, nesse caso Dorje Drakden, assumisse completamente o corpo e "paralisasse" os skandhas (elementos) de seu "hospedeiro".

${ }^{16}$ Ven. Thupten Ngodrup, em palestra pública - que precedeu a apresentação do filme The State Oracle of Tibet - que ocorreu em Brisbane, na Austrália, em 31 de janeiro de 2013.

Debates do NER, Porto Alegre, ANo I5, N. 25, P. 29I-3IO, JAN./Jun. 20 I4 
A única coisa que é percebida pela maioria do público presente durante o transe do oráculo é que algo efetivamente se transforma no kuden (médium), o qual se comporta de forma completamente fora dos seus próprios padrões anteriores. A sensação é mesmo a de que o ser, até então "informe" ou invisível, do "espírito profético", "deixa" a sua forma anterior, assume o controle dos agregados do oráculo, usa os seus próprios agregados, particularmente os quatro agregados mentais - sensações, percepções, motivações e consciência - para comunicar a sua mensagem e, finalmente, após o transe, retorna à sua "forma invisível" original, permitindo que os constantes processos físicopsicos do kuden possam voltar ao seu fluxo anterior.

Como já foi relatado anteriormente, o corpo do Nechung assume características diferentes enquanto está sendo "usado" pelos agregados (skandhas) da "entidade", sugerindo que até mesmo o corpo "abandonado" do hospedeiro, não é algo permanente que é habitado temporariamente por uma outra consciência, mas sim que este corpo é um processo constante que ganha dimensões diferentes enquanto está conectado com os "novos agregados" trazidos pelo espírito. Uma vez que se trata de um processo contínuo, desprovido de qualquer essência ou identidade fixa, o corpo se torna suscetível a tais transformaçōes.

Além de adquirir a capacidade para suportar o peso do capacete extremamente pesado (que faz parte dos ornamentos específicos necessários para esta possessão), que em circunstâncias normais seria capaz de lhe quebrar o pescoço e, literalmente, matar o kuden, há duas outras transformaçôes físicas relevantes que suportam a nossa tentativa de compreender a maleabilidade do corpo. Para assegurar a autenticidade do espírito que está sendo incorporado que, neste caso específico, é Dorje Drakden, testes extensos são realizados. Antes de entrar no transe, por exemplo, o hálito do kuden é examinado para se certificar de que o mesmo é desprovido de qualquer odor forte, ou diferente do usual; durante o transe, o hálito é reexaminado. Se Dorje Drakden estiver de fato presente e a possessão for autêntica, o hálito passa a ter um odor bastante forte, semelhante ao álcool, que é tido como o cheiro de néctar. Segundo as lendas, quando no século VIII o mestre buddhista indiano Padmasambhava foi capaz de converter os chamados

Debates do NER, Porto Alegre, Ano I5, N. 25, P. 29I-3io, JAn./Jun. 2014 
cinco espíritos reis (rgyal po sku lnga), que haviam coletivamente assumido a forma de um noviço de oito anos de idade, ele ungiu a língua da criança com um algumas gotas de néctar, tal aroma foi mantido pelos espíritos como sinal de que estavam mantendo os votos que fizeram de proteger os ensinamentos de Buddha (Avedon, 1984, p. 212).

A segunda parte do chamado teste secreto, também evoca o período durante o qual Padmasambhava é dito ter conquistado esses espíritos. Durante o ritual de conversão, o mestre indiano teria colocado a ponta de seu dorje (rdo rje / s. vajra - um certo ritual com múltiplas pontas) sobre a cabeça da criança que estava ajoelhada à sua frente, para iniciá-la na doutrina e criar um laço de fidelidade. Para confirmar que a possessão do Nechung é genuína, e Dorje Drakden estava de fato presente, imediatamente após a conclusão do transe, os atendentes do médium rapidamente removem-lhe o capacete pesado e acolchoado, antes que ele comece a se engasgar com o peso, ao fazerem-no, é revelada uma marca bem definida de um dorje, o qual é claramente visível na coroa da cabeça do médium durante vários minutos. Esta marca é tomada como mais uma prova de que o kuden de fato havia sido possuído pelo mesmo espírito que fora pacificado e convertido por Padmasambhava no século VIII ${ }^{17}$.

\section{CONSIDERAÇÕES FINAIS:}

\section{VACUIDADE DO CORPO - INTERDEPENDÊNCIA DO SER}

Pode-se, então, identificar três transformações visíveis e constatadas no corpo do médium, ou seja, o aumento da força física associada à entrada no estado de transe, o aroma característico de néctar no hálito durante o transe e a marca do dorje na coroa da cabeça do médium no estado imediatamente pós-transe. Estas dramáticas transmutações físicas apoiam a nossa hipótese de que o agregado da forma (s. rūpa skandha) - associado com as teorias

${ }^{17}$ Ver Nebesky-Wojkowitz, Oracles and Demons, p. 420-421. Um relato alternativo deste encontro entre o mestre indiano e os espíritos dos cinco reis, atribuído a Ngawang Lozang Gyatso (Vo Dalai Lama), em History of Tibet, é citado por Lin Shen-Yu in Pehar, p. 19-20.

Debates do NER, Porto Alegre, ANo I5, N. 25, P. 29I-3IO, JAN./Jun. 2014 
descritas anteriormente de não-si e da vacuidade -, i.e., o corpo, é um fluxo, um processo constante passível de ser transformado pela interação com os elementos do espírito hospedado, neste caso Dorje Drakden. Esses elementos, que são uma série complexa de estados psicológicos transitórios, mas interligados, interagem com o fluxo-forma (o corpo) do oráculo Nechung, de maneira tal que isso é visivelmente percebido pela maioria dos participantes.

Apesar de não nos caber conjecturar sobre outras possibilidades interpretativas neste momento, para efeitos deste estudo específico, a hipótese aqui apresentada aborda algumas das bases filosóficas mais importantes do buddhismo em geral, e do buddhismo tibetano em particular, ao mesmo tempo que nos oferece uma compreensão razoável do processo de possessão, no caso particular do oráculo Nechung, em que se pode visivelmente notar uma transformação dramática do médium, além de ser um caso em que o "hospedeiro" fica completamente inconsciente durante o período do transe. Futuramente, seria bastante proveitosa a inclusão de uma análise das teorias e das práticas tântricas, além dos materiais etnográficos disponíveis sobre a tradição Bön, a qual precede a penetração buddhista. Todavia, essas inclusões ocupariam um espaço muito além do que o pertinente a este artigo e, por hora, nos contentamos em expor esta breve reflexão que tomou por base teorias centrais da filosofia buddhista, relativas ao "não-si" (s. anātman) e a "vacuidade" (s. Śūnyatā), que foram ornamentadas por fatores históricos, míticos, físicos, mentais, performáticos, buddhistas, não buddhistas, etc., no qual nos aparamos em uma única forma de prática oracular tibetana, o caso do Oráculo do Estado, o Oráculo Nechung.

\section{REFERÊNCIAS}

AHMAD, Zahiruddin. Trans. A History of Tibet by the Fith Dalai Lama of Tibet. Bloomington: Indiana University Press, 1995.

ARNOTT, Geoffrey. Nechung: A Modern Parallel to the Delphic Oracle?. In: Greece and Rome. Cambridge. v. 36.2. 1989. p. 152-157. 
AVEDON, John. In Exile from the Land of Snows: The Definitive Account of the Dalai Lama and Tibet Since the Chinese Conquest. New York: Knopf, 1984.

BELL, Christopher P. Tsiu Marpo: The Career of a Tibetan Protector Deity. Tese (Doutorado). Florida State University, 2006.

BELLEZZA, John Vincent. Spirit-mediums, Sacred Mountains and Related Bon Textual Traditions in Upper Tibet: Calling Down the Gods. Leiden: Brill, 2005.

. The Liturgies and Oracular Utterances of the Spirit-mediums of Upper Tibet - An Introduction to their bSang Rituals. Revue d'Etudes Tibétaines. Paris, v. 20, p. 5-31, 2011.

BERGLIE, Per-Arne. Preliminary Remarks on Some Tibetan Spirit Mediums in Nepal. Kailash - Journal of Himalayan Studies. Kathmandu, v. 4.1, p. 85-108, 1976.

BOYER, Pascal. Religious Thought and Behaviour as By-Products of Brain Function. In: Trends in Cognitive Science. Boston, v. 7.3, 2003. p. 119-124.

ELLINGSON, Ter. Arrow and Mirror: Interactive Consciousness, Ethnography, and the Tibetan State Oracle's Trance. Anthropology and Humanism. Virginia, v. 23.1, p. 51-76, 1998.

GIBSON, Todd. Notes on the History of the Shamanic in Tibet and Inner Asia. Numen. Massachusetts. v. 44. n.1, p.39-59, 1997.

GOODMAN, Steven; DAVIDSON, Ronald (Ed.). Tibetan Buddhism: Reason and Revelation. Albany NY: SUNY Press, 1992.

KAPSTEIN, Matthew. The Tibetan Assimilation of Buddhism: Conversion, Contestation, and Memory. New York: Oxford University Press, 2000.

KRESSING, Frank. The Increase of Shamans in Contemporary Ladakh: Some Preliminary Observations. Asian Folklore Studies. Japan, v. 62, p. 1-23, 2003.

Debates do NER, Porto Alegre, ANo I5, N. 25, P. 29I-3IO, JAN./Jun. 2014 
LAWSON, E. Thomas; McCAULEY, Robert N. Rethinking Religion: Connecting Cognition and Culture. Cambridge: Cambridge University Press, 1990.

LÉVI- STRAUSS, Claude. Structural Anthropology. New York: Basic Books, 1963.

LEWIS, Ioan M. Ecstatic Religion: A Study of Shamanism and Spirit Possession. London: Routledge, 2003.

LIN, Shen-Yu. Pehar: A Historical Survey. Revue d'Etudes Tibétaines. Paris. v. 19, p. 5-26, 2010.

MACDONALD, Ariane. Le culte de Pehar et de Ci'u dmar-po dans la tradition écrite et orale. Histoire du monastère de Gnas-chung et de ses médiums (suite). In: Annuaire de l'Ecole Pratique des Hautes Etudes. Paris, 1978. p. 1139-1145.

. Les rivalités politiques et religieuses centrées sur Samye au XVIe siècle. La lignée spirituelle du Ve Dalai-Lama dans la littérature, dans l'histoire, et dans l'art". In: Annuaire de l'Ecole Pratique des Hautes Etudes. Paris, 1978. p. 1023-1030.

MARTIN, Dan. The Star King and the Four Children of Pehar: Popular Religious Movements of the 11th- to 12th-Century Tibet. Acta Orientalia Academiae Scientiarum Hungaricae. Budapeste. v. 49, p. 171-195, 1996.

McCAULEY, Robert N.; LAWSON, E. Thomas. Bringing Ritual to Mind: Psychological Foundations of Cultural Forms. Cambridge: Cambridge University Press, 2002.

NEBESKY-WOJKOWITZ, Réne. Oracles and Demons of Tibet: The Cult and Iconography of the Tibetan Protective Deities. Kathmandu: Book Faith India, 1993.

POWERS, John; TEMPLEMAN, David. Historical Dictionary of Tibet. Lanham MD: Scarecrow Press, 2012.

Debates do NER, Porto Alegre, Ano I5, N. 25, P. 29I-3io, JAn./Jun. 2014 
ROERICH, George. Trans. The Blue Annals. Calcutta: Royal Asiatic Society, 1949.

SAMUEL, Geoffrey. Civilized Shamans: Buddhism in Tibetan Societies. Washington DC: Smithsonian Institute Press, 1993.

SCHMIDT, Erik Hein (tradução). The Lotus Born: The Life Story of Padmasambhava. Boston: Shambhala, 1993.

SIDKY, Homayun. The State Oracle of Tibet, Spirit Possession, and Shamanism. In: Numen. Massachusetts, v. 58, 2011. p. 71-99.

TAUSSIG, Michael. Shamanism, Colonialism, and the Wild Man: A Study in Terror and Healing. Chicago: University of Chicago Press, 1991.

TEWARI, Ramesh. Pre-Buddhist Elements in Himalayan Buddhism: The Institution of Oracles. Journal of the International Association of Buddhist Studies. Heidelberg. v. 10.1, p. 135-156, 1987.

WALLACE, B. Alan (Editor). Buddhism and Science: Breaking New Ground. New York: Columbia University Press, 2003.

Recebido em: 06/06/2013

Aprovado em : 20/04/2014 